\title{
Biologists make plea to NIH to invest in s upercomputer centre
}

[WASHINGTON] A group of biologists who use supercomputers to model the structure and mechanisms of biological molecules is urging the US National Institutes of Health (NIH) to boost its investment in highperformance computing.

The group, which gathered last week at a meeting in Rockville, Maryland, sponsored by NIH's National Center for Research Resources (NCRR), was virtually unanimous in arguing that NIH is lagging behind leading federal agencies - namely, the Department of Energy and the National Science Foundation (NSF) - in investing in supercomputers.

The suggestions of the group. which will be given to NCRR, include the recommendation that NIH fund a single, central facility that operates a large 'teraflop' machine, the next generation of supercomputer.

The biologists said that the next generation of 'teraflop machines' - a hundred times more powerful than existing supercomputers - would give qualitative gains, including the possibility of modelling protein-protein recognition and self-assembly. They also spoke of the possibility of studying larger molecular systems, rather than, say, isolated enzymes, leading to a more sophisticated approach to drug discovery.

They also say the machines would allow far longer simulations. As it stands, studies of the changing forces within biological molecules are limited to nanosecond glimpses, preventing tests of theories of molecular structure and function in the real world, where changes take a million times longer.

But "NIH for some reason is just not there," says J. Andrew McCammon, professor of pharmacology and chemistry at the University of California, San Diego. He uses the San Diego Supercomputer Center, one of two major centres funded by the NSF.

"The NIH are not a player in this highperformance computing business, and they really need to be," said Klaus Schulten, who chaired the meeting and heads an NCRRfunded mid-level computer resource at the University of Illinois at Urbana-Champaign. He added that NIH was being asked "with a louder and louder voice" to fund computing centres, but that the biomedical agency has "not addressed the role of computing... as forcefully as some other agencies".

The meeting was organized to list the advances that teraflop machines would allow, to present NIH with a convincing argument for investing the multi-million dollar sums required to make high-performance machines more broadly available.

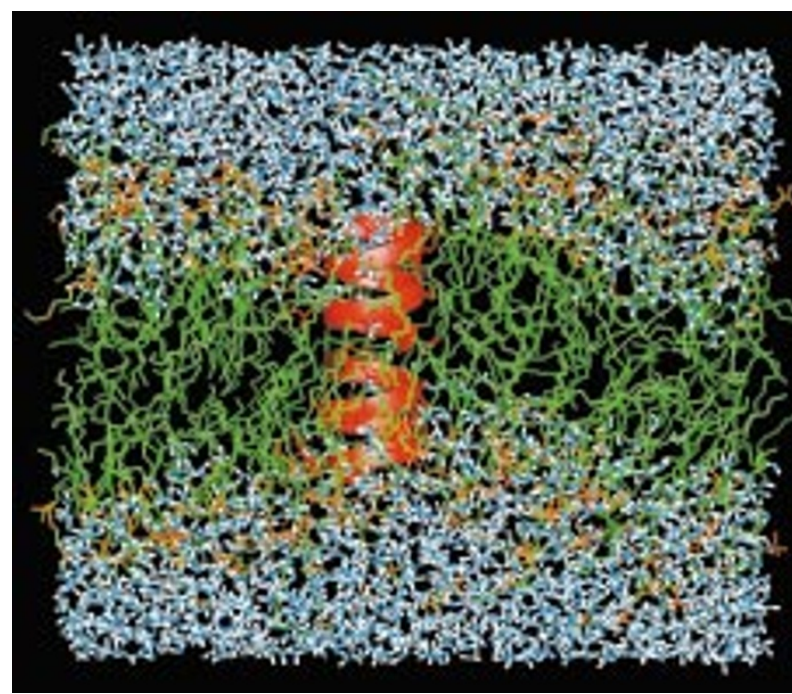

Complex number: this computer image generated at the National Center for Supercomputing Applications at the University of Illinois shows a model ion channel in a lipid bilayer embedded in a solvent milieu. The image demonstrates the complexity of macromolecular systems. The centre is funded by the National Science Foundation.

The NIH supports only one \$3.9 million, dated supercomputer centre at a National Cancer Institute campus at Frederick, Maryland. Biologists do most of their work at a centre in Pittsburgh, mainly funded by the DoE, and at the NSF-funded centres at San Diego and Urbana.

NSF invests $\$ 70$ million annually in its two centres. And the $\$ 366$ million government-wide computing initiative recently announced by Vice-President Al Gore allocates only $\$ 6$ million to NIH, of which just $\$ 2$ million goes to "advanced computing" (see Nature 397, 285; 1999).

The use of the NSF centres by biologists is growing rapidly. Between June 1997 and May 1998, one-third of the time at the NSF supercomputer centres was allocated to (mostly molecular) biologists. This is a 54 per cent increase on the previous year.

"There's a very clear trend that the major usage and the large projects are swinging over from being physics- and astronomydriven to being biology-driven," says Eric Jakobsson, a senior research scientist at the NSF-funded National Center for Supercomputing Applications at the University of Illinois at Urbana-Champaign. "In a couple of years the cycles for big users will probably be about 50 per cent biology."

But this does not satisfy biologists, who feel as squeezed as the physicists and astronomers with whom they share the machines, and say that 'cycle drought' - the chroniclack of computer time - should compel NIH to act on their behalf. Overall, requests for time on the leading computer at San Diego exceed that available by a factor of four or five.

Harold Varmus, the NIH director, commissioned a working group on biomedical computing last year to produce a report that will be presented to his advisory committee

\section{Catalonia offers $\$ 16 \mathrm{~m}$ innovation grants}

[BARCELONA] The government of the Spanish autonomous region of Catalonia has launched a US\$16.6 million programme of non-repayable capital grants to encourage the entrepreneurial activities of scientists.

The objective of the scheme, called Network of Centres for Technological Innovation Support, is to finance $\mathbf{1 0 0}$ research teams for the next three years. Each group will receive about $\$ 55,000$ a year. Nine research teams have already been approved for funding since the scheme was launched last month.

The scheme is intended to support researchers who have ideas about how their results could be turned into commercial propositions, but who lack access to the necessary funds. Successful grant applicants will be able to build up the resources needed to offer their knowledge to private industry, or to create their own companies.

The initiative stems from a desire by the government of Catalonia to boost links between the scientific and business communities.

Applicants will have to demonstrate potential commercial interest in their work. They must produce a strategy suggesting how the project might become self-financing within three years. If, after this period, the researcher has not achieved a profitable result, the grant will end. 
in June. Part of the group's remit is to investigate "the impediments biologists face in utilizing high-end computing".

Larry Smarr, director of the NSF centre at the University of Illinois and a co-chair of the working group, says he agrees that supercomputers offer a "tremendous opportunity" to biologists. But he says there is a lively debate in his group on how to increase NIHfunded high-performance computing, and no consensus has been reached. The group is looking at the extent to which enlarging existing 'clusters' of personal computers or workstations in research groups could meet the need for advanced computer power.

Also, should NIH invest in a new supercomputer centre, build on the one at Frederick, or develop several smaller centres dedicated to applications such as organ simulations, genomics and the study of biopolymer systems? Or should it add its resources to one of the NSF or energy department centres, where it could profit from cross-pollination with the physical sciences and the existing infrastructure? "My guess is that there will be some sort of combination of solutions," says Smarr.

But, he says, whatever his group recommends, the supercomputer needs of biologists will not be assessed in a vacuum. "Clearly the science that's done with supercomputers can't be done any other way," says Smarr. "But there are vastly more biologists that use the web than use supercomputers. If [NIH] has only so many dollars, then it has to make decisions across the spectrum."

Many of those at last week's meeting argued that the kinds of advances foreseen by advocates of teraflop machines do not fire the imaginations of ordinary biologists. They pointed out that, to sell high-performance computing to NIH, enthusiasts will have to chart a course from these improvements to tangible health benefits.

That's not difficult, says McCammon. He points out that the HIV protease inhibitors now prolonging thousands of lives were developed in part with computational methods from his laboratory.

He says that his lab's work on the neuroenzyme acetylcholinesterase, discovering computationally how the enzyme gets its speed and specificity of action, is laying the groundwork for better drugs for neurological disorders from Alzheimer's disease to glaucoma.

Others said that, regardless of the power of supercomputers or NIH investment, their availability will be partly wasted unless the broader community of biologists becomes better educated in their use.

There is "huge ignorance" among ordinary biologists about how to use computational tools, said Carol Post of Purdue University, Indiana. "The universal problem is not hardware," adds Smarr. "All the biologists [the working group has interviewed] say "we need more training.” Meredith Wadman

\section{Mixed funding fortunes for UK research universities}

[LONDON] England's top five research universities are - once again - the biggest beneficiaries in this year's allocation of $£ 855$ million (US\$1.37 billion) of research funds from the Higher Education Funding Council for England (HEFCE).

In contrast, the small cash increase in research income for most other large research universities represents a drop in real terms. Some, including the universities of Birmingham, Liverpool and Newcastle, even see the cash value of their HEFCE funds fall.

Overall, HEFCE research funds for England's 76 universities and 58 colleges and specialist institutions will rise by 3.5 per cent, one per cent above the rate of inflation. This year, HEFCE has a total university teaching

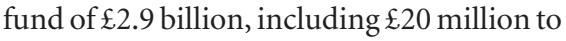
support wider participation by students from disadvantaged backgrounds.

The largest increases in research incomes, however, averaging 6.8 per cent, go to the universities of Oxford and Cambridge, Imperial College and University College, London (UCL).

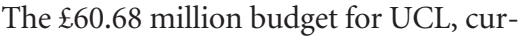
rently third in the HEFCE research league table, brings it within reach of the University of Cambridge ( $£ 61.3$ million), currently in second place. The University of Oxford ( $\mathfrak{E 6 3 . 0 5}$ million) is ranked first. Imperial College ( $£ 54.4$ million) is ranked fourth, with King’s College London ( $\$ 35.19$ million) fifth.

Next year, UCL may well overtake the University of Cambridge, breaking the longestablished Oxbridge duopoly at the top, as Oxford and Cambridge's comparatively large increases for this year partly reflect the transfer of $£ 6$ million in undergraduate fees from the Department for Education to HEFCE.

Brian Fender, chief executive of HEFCE, says this year's allocation is a "modest" increase compared to last year's 14.6 per cent increase in research funds. But this, he says, anticipates the extra $£ 600$ million for research infrastructure announced last year as part of the Comprehensive Spending Review.

HEFCE funds are one pillar of Britain's dual-support research-funding system, and are used to pay for salaries and some infrastructure. Money for research grants comes from the five research councils.

HEFCE funds are allocated according to the results of the Research Assessment Exercise, which evaluates the quality and volume of university research. The next exercise will be in 2001.

Ehsan Masood

\section{US Nobel w inners back stem-cell research}

[WASHINGTON] A group of 33 Nobel laureates is urging the US government to stick to its promise to fund research using human embryonic stem cells, despite a ban on funding research on human embryos.

The group wrote to President Bill Clinton and the US Congress last week warning of the "serious negative consequences" of not allowing federally funded scientists to work with the cells (see Nature 397, 185; 1999). Such research shows great promise for the development of cell and tissue therapies for diseases from diabetes to Alzheimer's.

But controversy has arisen because some stem cells are derived from embryos left over after fertility treatments. Opponents of abortion argue that federally funded research with these cells breaks the law prohibiting federal funding of human embryo research.

The letter argues that if federally funded scientists are not allowed to proceed it will "bar the majority of the nation's most prominent researchers who are supported by the National Institutes of Health and the National Science Foundation... from engaging in this critical research".
It adds that the use of peer-reviewed federal funds for stem-cell research "is our best assurance that research will be of the highest quality and performed with the greatest dignity and moral responsibility".

The letter was written and circulated by Paul Berg, the Stanford University biochemist who chairs the public policy committee of the American Society for Cell Biology. Its signatories include David Baltimore, president of the California Institute of Technology, J. Michael Bishop, chancellor of the University of California at San Francisco, and Joshua Lederberg, professor emeritus at Rockefeller University in New York.

"We had been concerned about the issue on Capitol Hill and wanted to make it very clear that the scientific community is behind stem-cell research and its funding," says Tim Leshan, director of public policy at the society.

The initiative comes after 70 conservative congressmen and seven senators wrote to Donna Shalala, Secretary of Health and Human Services, to protest at the department's decision to fund the research (see Nature 397, 639; 1999). 